C2017. Licensed under the Creative Commons Attribution-NonCommercial-NoDerivatives 4.0 International http://creativecommons.org/about/downloads

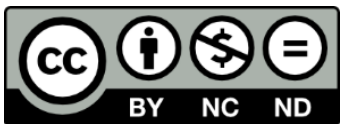

The published version of East, Robert and Ang, Lawrence (2017) Making progress in marketing research. Australasian Marketing Journal (AMJ), 25(4), pp. 334-340 can be found at https://doi.org/10.1016/j.ausmj.2017.10.010 


\section{Making Progress in Marketing Research}

Robert East, Emeritus Professor, Kingston Business School, London and Ehrenberg-Bass Institute, UNISA, Adelaide

Lawrence Ang, Associate Professor, Macquarie University, Sydney

Robert East, 19, Archibald Road, London, N7 0AN, UK

Tel: +447703724437

No fax.

R.East@kingston.ac.uk

Lawrence Ang, Macquarie University, Sydney NSW 2109, Australia

Tel: 61-2 98509135

Fax +61-2 9850-6065

Lawrence.ang@mq.edu.au 


\title{
Making Progress in Marketing Research
}

\begin{abstract}
Progress in any subject requires the origination of theoretical ideas. Often, new theoretical ideas are derived from unpredicted findings. Some methods, such as surveys, yield more unpredicted findings compared to experiments and too great an emphasis on testing theories by experiment may therefore lead to fewer new ideas. We argue that researchers in marketing and other social sciences should give more consideration to methods that produce large amounts of evidence; by doing so, they may speed up the development of their subject.
\end{abstract}

Key words: Insight; scientific progress; survey; experiment 


\section{How does marketing research progress?}

In the social sciences, much attention has been given to the status of theories and how these theories should be tested (e.g., Kuhn, 1962; Popper, 1980; Wilkinson, 2012; Kenworthy and Yadav 2010, Sparks, 2016). Rather less attention is directed to the genesis of these theories. How do new ideas come into the minds of researchers in the first place? What helps or hinders this creative thinking? Let us start by admitting that much scientific activity is not that creative. Many of our findings rest on the application of established thinking but, occasionally, we get evidence that raises questions about widely held beliefs and practices or suggests an answer to a persisting problem. Such findings may redirect our work and we need to foster the circumstances that create this sort of outcome.

What will assist the production of new theoretical ideas? One way of exploring the origin of these ideas is to look at the scientists themselves: what drives these researchers? How do they conduct themselves? This has been done by Sternberg, Fiske and Foss (2016) but their account tends to focus on the individual traits of the behavioural scientists they studied and these are not easily modified or emulated, which limits the change that is possible via this route. Another approach could focus on the social aspect. Research is usually conducted collaboratively with fellow researchers. Thus, if we ask how new thinking came about, the answer often relates to interactions with others within the social setting in which science is performed. The multiple authorship of many papers suggests that new ideas prosper in an interactive context but we also note that some of the greatest contributors to science acted individually (e.g. Newton, Darwin and Einstein), so this matter is not clear cut. We can also look at the established practices governing science - how can the reviewing process be improved, for example? Reviewers are 
often strongest on the methodological aspects of research and may not understand the new ideas or attach enough importance to them when they do understand. In contrast to such approaches, our focus is quite narrow. After a discussion of what is involved in idea generation, and noting that new ideas are often generated by new data, we look at the data yield provided by two different methods: experiments and surveys. We argue that we should invest more effort in methods that produce large amounts of data because it is here that new findings may emerge that require a new explanation. We suggest that survey work is undervalued as a source of new ideas in social science.

\section{Testing new ideas}

In marketing, many factors may operate at the same time to produce outcomes; in this respect, it belongs with other social sciences, and subjects such as biology, medical research and environmental sciences. This means that an explanation for an effect may be partial and prediction uncertain. In contrast, there are cases in the physical sciences where new theories are dramatically confirmed by classic experiments and observations. For example, in physics, Einstein predicted how much light would bend as it passed through the gravitational field of the Sun. His calculations of the deflection angle from a straight-line path were verified in an observational study of the solar eclipse in May 1919 (Kennefick, 2009). More recently, the gravitational waves predicted by Einstein's general theory of relativity were detected on September 14, 2015 in two large-scale experimental physics observatories in Washington State and Louisiana, U.S.A. This was hailed as a triumphant confirmation of Einstein's theory (Conover, 2016). 
In the social sciences, such crucial tests are hard to find. Because many factors may be at work to produce an outcome, the effect of one factor may be small. Sometimes, there is no theory to test; instead we have a problem to solve or are simply curious, and for some practical purposes we may be content to establish facts such as the relative purchasing power of different population segments. But in marketing research, we look for explanations. For example, why does the longterm effect of advertising relate to the short-term effect? Why are certain factors associated with the impact of recommendation? Sometimes these explanations rest on simple relationships; at other times, they may be cast as a formal theory. So, we have findings, their possible explanations, the testing of these (competing) explanations and subsequent evaluation which may give rise to more ideas and tests. In this rolling process, the generation of new ideas is essential.

\section{Forming new ideas}

Two types of new idea can be identified. First, we have insights that allow us to reframe our thinking in a new way. Such insights may arise from a single odd finding, strange association, or contrary result which does not fit existing thinking. Second, and perhaps more commonly, we recognise that an already established solution can be applied to a problem. In practice, it may be hard to say whether a new idea is a case of insight or recognition since some applications of existing thinking involve considerable imagination. These processes, insight and recognition, are the means whereby we identify research questions, make sense of unfamiliar findings and sometimes see new ways of investigating a problem. Nisbett and Wilson (1977) have pointed out that the mental mechanisms giving rise to insights are not directly accessible: we know that we have had a new idea but are not conscious of how we came to think it. This means that we must study such processes indirectly, by looking at the circumstances associated with them. 
Of the two processes, insights particularly interest us because these seem most likely to redirect research in a major way. In the physical sciences, the insights of intellectual giants such as Newton, Darwin, Einstein, Lavoisier and Maxwell opened new fields of inquiry and changed the conduct of their discipline. How do insights emerge? Wallas (1926) proposed a four-fold model of the creative process: preparation, incubation, illumination and verification. We are doubtful about this neat order of phases and suspect that illumination (insight, recognition) is more distributed but preparation in Wallas' classification does suggest that there is often a period of assembling and reviewing the available evidence. To ground this discussion, we review cases where major advances in our understanding of marketing and psychology have been made, and consider how such breakthroughs came about. If we can show how our subject advances in practice, we may be able to stimulate such advance by focusing on methods that are associated with progress. To reflect the irregular pattern of new understanding, we include one case (relationship marketing) where the initial advance has been somewhat checked by contrary findings.

\section{Examples}

\section{Stationary markets}

One well-established field has been the modelling of near-stationary markets. Most markets are close to stationary and researchers led by Ehrenberg and Goodhardt (Ehrenberg 1988) have shown that individual household purchasing has a near-Poisson pattern while the distribution of average household purchasing is close to a gamma distribution (with many light buying households and few that are heavy buying). Combining these distributions, they showed that 
aggregated brand purchase was closely predicted by a negative binomial distribution (NBD).

This work was extended to all the brands in a category where a Dirichlet distribution was shown to fit. This research started when Andrew Ehrenberg was working in market research and a brand, Cadbury's Drinking Chocolate, seemed to have an unusually high purchase level (Ehrenberg, undated). One idea was that the brand had an excess of heavy buyers. To explore this, attempts were made to model the buying distribution, with the NBD fitting very neatly and showing that there was no excess of heavy buyers.

In this case, insight did not reveal the solution. The NBD was the second distribution tested by Ehrenberg; thus, the approach was by trial and error, though by someone who already knew what might work which attests to the importance of the preparation stage in Wallas' model discussed earlier. The fit of the NBD was repeated for other brands and Ehrenberg realised that he had found a pattern with wide application. Reading Ehrenberg's (undated) account of the research in this field, it seems that some original thinking was involved. The most prominent was the extension of the work from the brand to the category (Goodhardt, Ehrenberg and Chatfield, 1984). Ehrenberg (undated) credits his colleagues Chatfield and Goodhardt with the insight that the Dirichlet distribution would model category-level data.

Goodhardt (personal communication) reports two cases of startling findings that forced a reassessment of existing assumptions in this field. The first occurred when he studied TV programmes that were split into two halves and aired at different times. He found that many viewers of the first half failed to see the second half and that their place was taken by others who had not seen the first half. It appeared that the viewing of split programmes had a substantial 
random component and was thus stochastic to a much greater extent than he had anticipated. In the second case, Goodhardt described the purchase patterns observed in adhesive dressings (e.g., Elastoplast, BandAid). The researchers were interested in measuring the effect of a forthcoming ad campaign and, to induce new purchase in their population sample over the period of the campaign, they bought the adhesive dressings from those that had them (about $60 \%$ of the sample). After the advertising campaign, these people were checked to determine their rate of repurchase. To the surprise of the investigators, only about $20 \%$ had restocked. They also investigated the $40 \%$ who had not previously had a stock of adhesive dressings and found that here too, about $20 \%$ had purchased in the interval. These findings led the researchers to a new way of thinking about this market: all households were users but a proportion were out of stock at any one time. Again, there was a strongly stochastic aspect to purchase.

\section{Heuristic mechanisms}

A second example of scientific advance comes from psychology. This is the research on heuristic thinking accumulated by Kahneman, Slovik and Tversky (1981) and their many followers. This work, summarised by Kahneman (2012), has focused on the automatic processes in thinking that often displace more rational analysis. There have been some modifications to the interpretation of evidence in this field but the idea of heuristic thinking and the specific mechanisms involved are now generally supported. Prospect theory, dealing with how decisions are made, was a later development of this work (Tversky and Kahneman 1992). Kahneman's (2012) account of how the research evolved indicated that there was an extensive period of discussion and speculation between him and Tversky which resulted in many "what if" scenarios, simple experimental trials and the eventual assembly of a corpus of findings, many of which were contrary to assumptions 
made by those who assumed that thinking proceeded in a rational manner. For example, the availability heuristic leads people to think that things they can readily recall are more likely. This induces bias when relatively rare but dramatic events are easily recalled; an example is the number of road deaths, which people tend to overestimate in countries with low road mortality, such as the UK, where the annual death toll on the roads is only about 1,800. From Kahneman's account of this work, it appears that the findings were not always anticipated and much of the work was driven by curiosity rather than by a clear idea of what might be expected.

\section{Relationship marketing}

A third example is relationship marketing (e.g. Berry 1983, Grönroos 1983, Reichheld and Teal 1996). Relationship marketers have claimed that established customers are better value than new customers because they buy more, recommend the brand more and cost less to service. However, as more evidence has accumulated, some of these claimed advantages of established customers have lost support. East et al. (2006) found that, on average, long-term customers did not recommend more and Reinartz and Kumar (2000) found that these people were not always cheaper to service. Other researchers (Sharp 2010, Romaniuk and Sharp 2016) have argued that the related matter of brand expansion is best achieved by customer acquisition, citing new evidence (Riebe et al 2014). Relationship marketing may be the best policy in certain categories but its advantages seem overstated.

\section{Massing the evidence}

In these three cases, two facts stand out. First, a mass of evidence is important. It was the accumulation of evidence against some of the claims made in relationship marketing that cast 
doubt on a long-held principle; and it was also the mass of consistent evidence that led to generalisations about heuristic decision making and purchase patterns in stationary markets. Often, replications contribute to this mass of evidence when researchers conduct the same study on a different population or context. Second, the theory-first approach that applies to some developments in the physical science, does not seem to be necessary in social science - if the examples selected are typical.

Sometimes a theory is tested but, often, this theory is sketchy. At other times, research is designed to answer practical questions or is conducted out of simple curiosity. In the case of relationship marketing, it is questionable whether this field ever gave rise to a theory (as opposed to a working principle) and in the case of stationary market theory, the theory came second, after data had been gathered. Regarding heuristic decision making, it looks to us from Kahneman's (2012) review that, initially, the researchers lacked a well-formed theory about what they would find and that the insights came after the evidence. Patterns of this sort have led to an emphasis on an evidence-first approach by some leaders in marketing research. This position was developed by Ehrenberg $(1993,1995)$ and Bass $(1995)$; they claim that scientific advance in marketing comes about mainly by the gathering of evidence from which empirical generalisations are made; then, more abstract explanations or theories may follow.

\section{Empirical generalisations}

The most famous of the empirical generalisations coming from Ehrenberg's work is Double Jeopardy. In its positive form, this is that large brands have both greater penetrations and greater purchase frequencies - more people buy them and these people buy them more often - and that, of the two, penetration varies most over normal purchase intervals. In consequence, a change in market share comes about more by change in penetration than by change in purchase frequency. 
Based on such evidence, marketers are advised to focus on raising penetration by acquiring more new customers when they are trying to enlarge a brand's share (Sharp 2010).

However, we are cautious about the value of empirical generalisations. In the case of stationary market research, empirical generalisations summarise the findings but, here, the logic of statistical reasoning controls much of what is found. It is possible to derive a closed-form equation linking purchase frequency and penetration - these variables are not accidentally related. This means that exceptions to the Double Jeopardy pattern occur only when circumstances overpower the normal statistical relationship between penetration and frequency, and they rarely do so. A similar case is the multiplier effect in economics. When additional money is injected into the economy, it allows people to spend more, which benefits others who will, in turn, use their gains to spend more, and so on; this successive spending usually boosts economic activity. This feedback process may still fail when a whole population becomes exceptionally cautious but the pressure of money circulation is strong. Such logical/statistical principles are an important part of many theories. When these are dominant, they may produce empirical generalisations, though it is their logical basis that ensures the scope of the generalisation.

\section{Generalisation and explanation}

We normally seek explanation for a pattern of findings, even when the pattern cannot be summarised by a generalisation. Consider, for example, the research on the impact of positive and negative word of mouth (PWOM, NWOM) on the intention to buy a brand which was gathered by East, Hammond and Lomax (2008). Research on 19 categories showed that PWOM had more impact than NWOM - on average. Thus, a generalisation from this evidence is that PWOM has a stronger effect than NWOM on intention to purchase but this is not particularly 
useful since some categories showed that NWOM had more impact. Rossiter (2001, p18) points out "empirical generalizations, which are the more general type of data, are just averages." $\mathrm{He}$ goes on to argue that practically useful principles come from understanding the reasons for deviations from these averages. East, Hammond and Lomax searched for reasons why PWOM had more impact than NWOM in some categories and less in others. A regression analysis of the factors associated with change in intention to purchase showed that the strongest determinant was the probability of purchase before receiving word of mouth. PWOM has more effect when prior purchase probability is low and there is more scope for an increase in purchase. NWOM, on the other hand, has more effect when prior probability is high and there is more scope for a reduction. East et al found that when the prior probability of purchase was 0.5 , PWOM and NWOM had similar impact magnitudes. Thus, much of the greater effect of PWOM could be traced to the fact that most prior probabilities were below 0.5 . Here, the mass of data allowed the researchers to find an explanation for the uneven findings across categories but average effects were unilluminating.

The limitation of empirical generalisation is also illustrated by East et al. (2005), who examined Reichheld and Teal's (1996) claim that long-term customers recommend the brand more. They established correlations between customer tenure and claimed volume of recommendations in 23 services. The correlations ranged from four significant positive associations to four significant negative ones, with 15 insignificant relationships. The average correlation was -0.01 , which does not support Reichheld and Teal's claim. East et al. confirmed a negative finding for credit card service and a positive finding for car servicing by conducting replication studies on these categories, so these results are unlikely to be chance events. The mass of data collected allows the results to be interpreted. The researchers did not measure the factors associated with 
recommendation but it seems likely that interest in unchanging products such as credit cards and insurance tends to be lost quite rapidly and therefore the inclination to talk about them. Positive correlations may occur when the product is regularly refreshed, interest is rekindled, and there is something new to talk about (e.g. fashion stores) or when it takes a long time to know whether the service is any good (car servicing). Thus, more than one explanation may apply, as is common in social science. The data help us to formulate possible explanations but, as before, relying on average effects is unhelpful.

\section{Research on insight}

Insight is a sudden realisation that a problem can be solved or a task accomplished by the application of one or more new ideas. Klein (2013) has studied this by gathering examples where insight was involved in naturally occurring activity. He is critical of experimental research in this field which focuses on impasse problems in tightly specified circumstances. (In an impasse problem, the insight required is that a previously used assumption is no longer helpful and that alternatives must be examined.) Klein pointed out that insights may arise in other ways and found that naturally occurring insights were stimulated under five novel conditions: connections, coincidences, curiosities, contradictions, and creative desperation. Of these, connections were involved in $82 \%$ of his 120 examples of insight (sometimes more than one condition was involved). Klein cited Darwin's development of the theory of natural selection as a case where connections were made. Another might be the fit between the littorals of America and Africa which suggested the theory of continental drift to Wegener (1912). Klein suggests that people have more insights if they are exposed to a large amount of data which may stimulate new connections and produce coincidences, curiosities and contradictions. Therefore, we need methods that supply plenty of findings. 


\section{Resistance to new ideas}

Klein is also interested in the circumstances that prevent insights from being accepted. $\mathrm{He}$ suggested that progress from insights may be stymied when critics have flawed beliefs, lack relevant experience, have a passive stance or use overly concrete reasoning (seeking closure and avoiding new ideas). In 30 of his cases, the insight of one party was held back by others and it was often flawed beliefs that prevented recognition of the insight. In addition, a passive stance was found in 21 cases out of these 30 cases. Klein found that in two thirds of his 120 cases, experience was a necessary precursor to insight (to be insightful, a person needs a prepared mind). In many situations, we focus on eliminating error and this may result in new ideas receiving short shrift. This is certainly true of scientific research where there are many examples of new ideas being delayed by the scientific establishment. Relating to flawed beliefs, a major barrier to the acceptance of a new theory occurs when it is contrary to pre-existing theories, a version of status quo bias. Darwin's thinking was contrary to ideas of divine creation; Wegener's theory, which took decades to become accepted, was contrary to the pre-established idea that contours on the earth's surface were produced by cooling; Lavoisier's contemporaries were reluctant to abandon phlogiston theory, despite Lavoisier's contrary evidence.

One example quoted by Klein was the Australian doctor, Barry Marshall, who took ten years to get his evidence published on the role of helicobacter pylori in the causation of stomach ulcers. Marshall had initially been struck by two coincidences: one of his patients, who had a bacterial infection in the stomach, also had chronic stomach pain; another patient treated with antibiotics recovered from stomach pain. In his research, Marshall eventually showed that 13 patients with 
stomach ulcers all had helicobacter pylori. Despite illustrating the process by deliberately infecting himself, his papers implicating helicobacter in stomach ulcers were rejected.

Eventually, he moved to the USA, where his self-experiment created interest and public agencies took note. This example shows the hold pre-existing ideas have on the scientific community; it was thought that bacteria could not survive in the acidic environment of the stomach and there was a standard practice of treating stomach pain with antacids or surgery. This suggests that some new ideas may fail to make it or be long delayed because of the resistance encountered from the scientific community. Bryson (2003) documents many cases where new ideas languished for long periods before eventual acceptance. Klein claims that, often, persistence pays off but his method cannot demonstrate this because the cases where persistence did not pay off would not have made it to his sample. The power of status quo bias suggests that we should take this into account and give extra support to new ideas that challenge existing thinking.

Klein's method, using an ad hoc collection of examples, does not tell us how frequently insight is the key to new scientific advances. In some fields, there may be a range of potential solutions to a problem and advance comes about from working through the possible solutions rather than from "seeing" a new solution. This was partly the case in the development of knowledge on stationary markets and we suspect that this is often the case when an invention is developed. For example, there appears to have been little insight behind the development in agriculture of new varieties of cereal. When Norman Borlang began work on improving cereals in Mexico, dwarfing (to avoid wind damage), yield, nutritional value, drought tolerance and disease resistance were all seen as desirable outcomes in cereal breeding. In time, this programme bore fruit and in 1963 the Mexican wheat crop was six times larger than in 1944 and the new varieties 
were grown throughout the world. Borlang was awarded the Nobel Peace Prize in 1970 and an assessment of his work indicated that it saved a billion people from starvation. However, when reading the account of this remarkable research programme, only one insight was noticeable; this was when Borlang realised that he could speed up the development of new cereal varieties in Mexico by growing the cereal twice each year.

\section{Two methods of investigation compared}

If insights are important, we next ask if some methods are better than others in generating such insights because they produce more evidence than others. Below, we restrict ourselves to the comparison of the two most established methods of research, experiments and surveys.

\section{Experiments}

In the physical sciences, researchers may draw hypotheses from theory and then conduct a crucial experiment that tests these hypotheses. This is possible when the theory has been specified and factors of interest can be isolated so that other interpretations of findings are excluded. However, in the social sciences, there are many variables, populations and settings and multiple causes are at work (Campbell and Stanley 1963). By using controls, it is possible to gather findings for one set of conditions but a finding for one category, segment and context may not apply to other categories, segments or contexts so that many studies may be required to show any coherent pattern in the findings. This makes the generalisability of laboratory findings necessarily limited as has been discussed by East (2016); it is also one explanation why the attempts to replicate work in psychology and marketing are often unsuccessful (Open Science Collaboration, 2015, Hubbard and Armstrong 1994, Evanschitzky et al, 2007). 
Field experiments are better than lab experiments to the extent that they can cover the broad range of conditions that will usually apply when findings are applied. Thus, a field experiment comparing two ads gives a degree of confidence about the ads' relative effectiveness when they are aired but, even here, there are doubts because other variables may interact with the ads on test; for example, news stories may affect a test ad in a manner that is not likely to apply when the ad is aired later. Fifty-five field experiments were used to investigate long-term ad effect by Lodish et al. (1995). The researchers compared the extra sales in the test year (when the ads were aired) with the extra sales in the two years following. On average, the extra sales in the two later years were about the same as those in the test year, although only half of the brands that they studied showed a long-term effect. In this case, the empirical generalisation is useful. It means that, on average, an investment in advertising can pay back twice as much as people thought, based on a one-year evaluation. However, Lodish et al.'s evidence still requires a more detailed explanation: one likely contender is that the brand advertising was poor in many cases and, supporting this, Lodish et al. found that a long-term effect does not occur when there is no shortterm response to the advertising; a second possible explanation for no long-term effect is that sales effects are often cancelled out by competitive advertising.

One feature of the experimental test of hypotheses is that a finding that is predicted is a stronger result than one that is observed but not predicted. A happenstance finding may be one of many possible findings and may be "significant" because of chance whereas, if only one result is predicted, the significance level can be accepted at face value. This matter is well recognised and researchers normally test serendipitous findings further before acceptance. Because of their dubious significance, some serendipitous findings may be ignored but these findings are an 
important basis for new ideas, a feedstock for insight or recognition that may lead to new thinking in the subject. This is true of the physical sciences as well, as witnessed in the accidental discovery of penicillin by Fleming and the unpredicted discoveries in astronomy as more powerful telescopes become available. Roberts (1989) has catalogued many important discoveries in science where serendipity was involved. But experiments, because of their focused design, do not usually produce serendipitous findings. If the development of marketing, like other disciplines, rests in part on unanticipated findings, we should ask what methods will produce more findings of this sort.

\section{Surveys}

Unpredicted findings are common in observational studies, surveys and panel research.

However, observational studies are impractical when the focal behaviour is infrequent and panel research is designed to answer specific questions about consumer behaviour that may leave out matters of interest to the academic researcher. Surveys are more flexible; they are widely used in commercial market research. However, in academic work this method is less common because of the correlational nature of findings and the potential for response bias (Preisendörfer and Wolter, 2014).

Surveys have three important virtues that relate to gathering new ideas. One is that they can cover a wide range of situations, variables and sub-groups. Respondents can be interrogated about these different conditions and the data classified against them. This means that a single large survey can cover much more than the typical single controlled experiment. Second, surveys allow us to investigate phenomena that are inaccessible by other methods. Suppose we wish to study second-hand markets. These can take a variety of forms such as car boot sales, farmers' 
markets, charity shops, eBay, and person-to-person deals. Some observational studies are possible in specific settings and Internet records, if available, can also be analysed. However, if the interest is in a more complete understanding of the second-hand market, then the only way to study this whole area is by survey. This is especially useful if we are interested in how different segments of the population divide their purchase across new and second-hand markets and the extent to which online and offline channels are used. By enlarging our knowledge in this way, we may gain insights about how second-hand markets are used by sub-groups and the social conventions under which they operate. The point here is that the method widens our thinking and may give rise to insights that, otherwise, would not occur. After a survey of second-hand markets, it is likely that further questions will arise that merit investigation.

A third advantage of surveys is that they provide a substantial quantity of data, which if properly collected (see Dillman, Smyth and Christian, 2014; Preisendörfer and Wolter, 2014), can yield information useful for developing new marketing theories. All the variables measured in a survey, for instance, can be tested for association and unexpected correlations may be revealed. Some correlations may be interesting and worth testing in further research. Thus, serendipitous findings from surveys make them attractive. To illustrate this point, we give one example from a recent study that compared the factors that triggered positive word of mouth (PWOM) about durables and those triggering it about services (Lomax and East 2016). It was found that, whereas advertising instigated 7 per cent of the PWOM about services, it was responsible for 44 per cent of the PWOM about durables. The researchers speculated that the tangibility of durables made ads about them more mentally accessible and effective, and that there might be heavier advertising in the durables sector. These speculations will need to be verified in further research 
but the finding that a large proportion of PWOM about durables is stimulated by advertising means that a substantial part of the sales effect of durables advertising arises via PWOM carryover. Managerially, this suggests that one should pre-test how effective durable ads are in inducing this PWOM. Current ad pre-testing procedures offered by market research firms do not evaluate this effect. Here, a serendipitous survey finding leads to new thinking about ad testing.

To summarise this section, new ideas in marketing and social science usually rest on a substantial amount of data. The two different methods of gathering these data discussed here make different contributions. Controlled experiments test predicted relationships and provide findings that are strong but contextually limited so that large numbers of experiments are needed to establish the mass of data required for generalised findings. Surveys provide weaker findings but more of them, and can be used to probe topics that are otherwise inaccessible. The large volume of data from surveys make it likely that new facts and unexpected relationships may emerge when this method is used, and this may lead to new explanations. In this way, a relatively weak method may be crucial to the advance of understanding in our field.

\section{Big data}

The ability to spot patterns in large datasets is increasingly important and this type of data science is beginning to transform industries (Gutierrez, 2014). In recent years, a combination of three conditions has begun to revolutionise technology and, potentially, the way in which science is conducted. First, artificial intelligence has shifted from attempting to analyse data according to algorithms based on specific problems and has moved to general problem-solving programs. Second, substantial databases have been generated which allow computers using these general 
problem-solving programs to be trained. Third, the speed and power of computers has risen enormously so that massive amounts of processing can be done by programs using such databases. The result is seen in fields such as machine translation and pattern recognition which get better and better. In the case of games, such as Go, datasets are not needed because the computer can play the game millions of times and store successful plays (Guardian, $19^{\text {th }}$ October, 2017 “Game over: AI becomes world's best Go player in just three days"). The generality of the problem-solving process means that any databases can be examined and searched for relationships. This brute empiricism raises the possibility that the "data first" model of research will become more entrenched and will drive new discoveries. At the same time, the autonomy of the problem-solving procedures, and their relative inaccessibility, mean that no specific explanation of discovered relationships is presented. This raises problems for scientists they will have findings but few leads on what produces these findings.

\section{One further example}

We conclude with an example - how Darwin developed the theory of evolution. Although this is not an example in marketing it demonstrates one important point in our argument: the accumulation of large amount of evidence can lead to a highly useful theory; in this case, a theory that is so revolutionary, it forever changed our view of humanity.

The theory of evolution had its genesis when Darwin, on the 27th December of 1831, set sail on the HMS Beagle for a 5-year exploratory voyage around the world. The naval vessel surveyed the coast of South America, sailed the world, visiting both Australia and New Zealand, before returning to England. This voyage is quite extraordinary because such expeditions are rare, often 
hazardous, and in this case, of long duration and expensive. Darwin had only just graduated from Cambridge University with an Arts degree and was intending to become a clergyman. As an unpaid naturalist on the naval ship, his task was to study and collect worthwhile specimens for the museums back in England. On this task, Darwin was industrious. Specimens collected included rocks, animals preserved in spirits, plants and beetles, fossils of extinct animals, jaws and heads of animals, teeth of rodents, marine shells, snakes, toads, lizards, mice, animal skins, crustaceans, fish, seeds, animals, geological specimens, birds, tortoises, turtles, iguanas and corals. All specimens were meticulously numbered and described.

Although Darwin was not a formally qualified biologist, he was well trained in empirical research, and was enthusiastic about natural history. As HMS Beagle traversed the globe, Darwin had many opportunities to disembark, explore, observe, catalogue and reflect on how animals and plants survived in different terrains. Sometimes, what he saw both fascinated and shocked him. For instance, he was fascinated by cuttlefish being able to change colour and by the diversity of birds and reptiles flourishing on the Galapogos Islands. He observed that different species of finch live in each island, with each species possessing different types of beak depending on the kind of food they eat. Finches that lived in a habitat with a plentiful supply of nuts tended to have large strong beaks, while finches that fed on insects had small beaks to catch their prey. Another fact that puzzled Darwin was the number of large-animal fossils. Large animals need huge amounts of food and yet, curiously, the fossils of these animals were found where vegetation was sparse. Darwin theorised that, in the past, the plains on which the animals roamed must have been full of vegetation which, over time, had become sparse, leading to the 
extinction of the animal. These observations helped Darwin formulate his theory of evolution based on natural selection but this took a long time to emerge.

After the Beagle returned in 1836, Darwin began to work on his theory. The idea of evolution was not all together new at that time since the notion of "species transmutation" has long been debated, even before Darwin was born, and there were other theories of evolution postulated (e.g., the Larmarckian model). However, what is new was Darwin's idea of natural selection as the mechanism driving evolution at the population level. This did not occur to him immediately though. Although Darwin was aware that selective breeding of animals and plants can result in physical changes, he did not know how this would occur naturally, a conceptual impasse that he needed to overcome. His breakthrough came after reading Malthus' Essay on Population (1798) where it was argued that the rapid rise of the human population would threaten its existence through competition for resources. It gave Darwin the idea that the weak would die while those with favourable traits would survive. Those that survived then produced more progeny with these adaptive traits and evolve into a new species. This theory accounts for the great diversity of species around the world. Darwin would not have reached this understanding without first studying and sorting through his collections, including the fossils. It gave him an understanding of how plants and animals came to be distributed by adaptation to the environment, and that a failure to adapt would lead to extinction (Ghiselin, 1972).

In the summer of 1842, Darwin wrote a 35-page sketch of his theory based on the mechanism of natural selection. This mechanism can never be directly observed (unlike experiments). But Darwin could defend his theory by pointing to many verifying facts, strongly supported by many 
well-documented observations and specimens including fossils. Other scientists like Gould, the famous British ornithologist, independently verified that the finches Darwin collected were indeed different species. But more importantly, Darwin could collect all the evidence and present it in a systematic manner under one unifying hypothesis - his vera causa. This means either the theory of evolution had to be accepted or the facts explained in another way. But Darwin had assembled so many facts that his theory could not easily be dismissed (Ruse, 2014).

Although the theory of evolution is now widely accepted, it is easy to forget the difficulties Darwin faced in developing his theory and getting it accepted. At that time, very little was known about how living organisms flourished in other parts of the world or the terrain they inhabited. Furthermore, there was also no unifying theory that made sense of how a species originated and developed. The dominant theory on the origin of life at that time was that a species was stable and never changed and this made the evolutionary theory radical. The theory was also heretical because it contradicted the book of Genesis. For fear of a religious backlash, Darwin was reticent about publishing his theory. It was only in 1859 , some twenty years after he formulated his theory, that On the Origins of Species by Means of Natural Selection (Darwin, 1859) was published. The theory has predicted many subsequent findings in palaeontology, geology, genetics and developmental biology. Like many scientific theories, it was controversial when it was first formulated but fully vindicated in the end.

This diversion into the story of evolution is a gentle reminder that harnessing a large amount of evidence should be something all scholars must aspire to achieve. We may not be able to find a 
vera causa of the stature of Darwin's but it is relatively easy to collect data in our field. At least our subjects can communicate with us!

\section{Conclusion}

This paper draws attention to the challenges our discipline faces in generating new ideas by insight and recognition. New ideas are stimulated by unexpected findings. Thus, we should be more positive about methods that produce substantial amounts of data from which connections, contradictions and novelties may emerge and oblige new thinking. Surveys, when well executed, are well placed to achieve this. Experiments, particularly controlled experiments, are more limited in this regard. This means that the examination of large data sets and the crafting of quality surveys should be part and parcel of doctoral training. We hope our contribution will stimulate debate in the community.

\section{References}

Bass, F.M. (1995). Empirical generalizations and marketing science: A personal view, Marketing Science, 14(3), Part 2 of 2, G6-G18.

Berry, L.L. (1983). Relationship Marketing. In L.L. Berry, G.L. Shostack, and G.D. Upah (eds), Emerging Perspectives on Service Marketing, Chicago: American Marketing Association, $25-28$.

Bryson, B. (2003). A Short History of Nearly Everything, London and New York: Doubleday.

Campbell, D.T. \& Stanley, J. (1963). Experimental and Quasi-Experimental Designs for Research. Rand McNally, Chicago. 
Conover, E. (2016). Year in review: Gravitational waves offer new cosmic views. Downloaded in March, 2017 at https://www.sciencenews.org/article/gravitational-waves-top-science$\underline{\text { stories-2016 }}$

Darwin, C. (1859). On the Origin of Species by Means of Natural Selection. Cambridge University Press, Cambridge.

Dillman, D.A., Smyth, J.D. and Christian, L.M. (2014). Internet, Phone, Mail, and Mixed-Mode Surveys : The Tailored Design Method $4^{\text {th }}$ Edition, John Wiley \& Sons, Inc. Hoboken New Jersey, U.S.A.

East, R. (2016). Bias in the evaluation of research methods, Marketing Theory, 16(2), 219-231.

East, R., Gendall, P., Hammond, K. and Lomax, W. (2005). Consumer loyalty: Singular, additive or interactive? Australasian Marketing Journal, 13(2), 10-26.

East, R., Hammond, K. \& Lomax, W. (2008). Measuring the impact of positive and negative word of mouth on brand purchase probability, International Journal of Research in Marketing, 25(3), 215-224.

East, R., Hammond, K. and Gendall, P. (2006). Fact and fallacy in retention marketing, Journal of Marketing Management, 22(1-2), 5-23.

Ehrenberg, A.S.C. (undated). My Research in marketing: How it happened, Contribution to the "Life and Times" column of Marketing Research, AMA. https://archive.ama.org/archive/ResourceLibrary/MarketingResearch/Pages/2004/16/4/MRWi nter04Ehrenberg.aspx

Ehrenberg, A.S.C. (1993). Theory or well-based results: Which comes first? In Laurent, G., Lilien, G.L. and Pras, B. Research Traditions in Marketing, 79-108, Kluwer Academic Publishers, Dordrecht. 
Ehrenberg, A.S.C. (1988). Repeat Buying: Theory and Applications, 2nd edition, London: Charles Griffin \& Co., London.

Ehrenberg, A.S.C. (1995). Empirical generalisation: Theory and method, Marketing Science 14(3), G20-G28.

Evanschitzky, H., Baumgarth, C., Hubbard, R., \& Armstrong, J. S. (2007). Replication research in marketing revisited: A note on a disturbing trend, Journal of Business Research, 60(4), 411-415.

Ghiselin, M. T. (1972). The Triumph of the Darwinian Method. University of California Press, California.

Goodhardt, G.J., Ehrenberg, A.S.C. and Chatfield, C. (1984). The Dirichlet: A comprehensive model of buying behaviour, Journal of the Royal Statistical Society, 147, 621-655

Grönroos, C. (1994). From marketing mix to relationship marketing: Towards a paradigm shift in marketing, Management Decision, 32(2), 4-20.

Gutierrez, S. (2014). Data Scientists At Work. Apress. Last accessed October 2017 at http://www.apress.com/us/book/9781430265986

Hubbard, R. \& Armstrong, J.S. (1994). Replications and extensions in marketing: Rarely published but quite contrary, International Journal of Research in Marketing, 11(3): 233248.

Kahneman, D. (2012). Thinking Fast and Thinking Slow, Penguin Books, London.

Kahneman, D., Slovic, P. and Tversky, A. (1982). Judgment under Uncertainty: Heuristics and Biases, Cambridge University Press, Cambridge, 117-28.

Kennefick, D. (2009). Testing relativity from the 1919 Eclipse - a question of bias. Physics Today, March, 37-42 
Kenworthy, T.P. and Sparks, J.R. (2016). A scientific realism perspective on scientific progress in marketing: An analysis of theory testing in marketing's major journals, European Management Journal, 34, 466-474

Klein, G. (2013). Seeing What Others Don't: The Remarkable Ways We Gain Insights, Public Affairs, New York.

Kuhn, T. (1962). The Structure of Scientific Revolutions, University of Chicago Press, Chicago.

Lodish, L.M., Abraham, M., Livelsberger, J., Lubetkin, B., Richardson, B. and Stevens, M.E. (1995). A Summary of fifty-five in-market experiments on the long-term effect of TV advertising, Marketing Science, 14(Part 2 of 2), G133-G140.

Lomax, W. and East, R. (2016). Talking about durables. Australasian Marketing Journal. 24(4), 262-66.

Malthus, T.R. (1798). An Essay on the Principle of Population As It Affects the Future Improvement of Society, with Remarks on the Speculations of Mr. Goodwin, M. Condorcet and Other Writers (1 ed.). J. Johnson in St Paul's Church-yard, London.

Nisbett, R.E. and Wilson, T.D. (1977). Telling more than we can know: Verbal reports on mental processes, Psychological Review, 84(3), 23159.

Open Science Collaboration (2015). Estimating the reproducibility of psychological science, Science, 349(6251), 943-954.

Popper, K. (1980). The Logic of Scientific Discovery (10th ed.). Hutchinson, London. Preisendörfer, P. and Wolter, F. (2014), Who is telling the truth? A validation study on determinants of response behavior in surveys, Public Opinion Quarterly, 78(1), 126146.Reichheld, F.F. and Teal, T. (1996). The Loyalty Effect, Harvard Business School Publications, Boston. 
Riebe, E., Wright, M., Stern, P., and Sharp, B. (2014). How to grow a brand: Retain or acquire customers? Journal of Business Research, 67(5), 990-997.

Reinartz, W. and Kumar, V. (2000). On the profitability of long-life customers in a noncontractual setting: An empirical investigation and implications for marketing, Journal of Marketing, 64(4), 17-36.

Roberts, R.M. (1989). Serendipity, John Wiley and Sons, Inc., New York.

Romaniuk, J. and Sharp, B. (2016). How Brands Grow: Part 2, Oxford University Press, South Melbourne.

Rossiter, J.R. (2001). What is marketing knowledge: Stage 1: Forms of marketing knowledge, Marketing Theory, 1(1), 9-26.

Ruse, M. (2014). Was there a Darwinian revolution? Yes, no, and maybe! Endeavour, 38(3-4), $159-168$

Sharp, B. (2010). How Brands Grow: What Marketers Don't Know, Oxford University Press, Melbourne.

Sternberg, R.J., Fiske, S.T. and Foss, D.J. (2016). Scientists Making a Difference, Cambridge University Press, New York.

Tversky, A. and Kahneman, D, (1992). Advances in prospect theory: Cumulative representation of uncertainty, Journal of Risk and Uncertainty, 5, 297-323.

Wallas, G. (1926). The Art of Thought. Jonathan Cape, London.

Wegener, A. (1912). 'Die Herausbildung der Grossformen der Erdrinde (Kontinente und Ozeane), auf geophysikalischer Grundlage', Petermanns Geographische Mitteilungen 63: 185-95, 253-6, 305-9, URL:http://epic.awi.de/Publications/Polarforsch2005_1 3.pdf. 
Wilkinson, M. (2013). Testing the null hypothesis: The forgotten legacy of Karl Popper? Journal of Sports Sciences, 31 (9), 919-920.

Yadav, M. (2010). The decline of conceptual articles and implications for knowledge development. Journal of Marketing, 74(1), 1-19. 